\title{
Site Fidelity and Annual Survival of the Western Yellow-breasted Chat (Icteria virens auricollis) at the Northern Edge of its Range
}

\author{
RenÉ McKibBin and Christine A. Bishop ${ }^{1}$ \\ Environment Canada, 5421 Robertson Road, Delta, British Columbia V4K 3N2 Canada \\ ${ }^{1}$ Corresponding author email: cab.bishop@ec.gc.ca
}

McKibbin, René, and Christine A. Bishop. 2012. Site fidelity and annual survival of the Western Yellow-breasted Chat (Icteria
virens auricollis) at the northern edge of its range. Canadian Field-Naturalist 126(2): 135-142.

We studied return rates, site fidelity, dispersal, and survivorship of an endangered population of the Western Yellow-breasted Chat (Icteria virens auricollis) in the southern Okanagan River valley, British Columbia, between 2001 and 2007. Between 2001 and 2006, we banded a total of 75 adults and 385 nestlings. Apparent survival for male Western Yellow-breasted Chats banded as adults was $65 \%$, and survival and recapture were constant across time. Other results were as follows: $44 \%$ of males and $13 \%$ of females banded as adults were re-sighted during the period $2002-2007 ; 33 \%$ of males and $10 \%$ of females were re-sighted the year after they were banded; $31 \%$ of males and $10 \%$ of females had fidelity to the study site where they were banded as adults; $10 \%$ of Western Yellow-breasted Chats banded as nestlings returned and, of these, $62 \%$ of males and 54\% of females returned to their natal study site to breed. The dispersal distance for males banded as adults $(n=5)$ that did not return to their sites ranged from $6.4 \mathrm{~km}$ to $42.9 \mathrm{~km}$. Natal dispersal ranged from $2.5 \mathrm{~km}$ to $15.6 \mathrm{~km}$ for males $(n=7)$ and $2.3 \mathrm{~km}$ to $2.6 \mathrm{~km}$ for females $(n=2)$; 16 males and 7 females banded as nestlings did not disperse. These findings contrast with predictions that species at the northern limit of their range will have low site fidelity and return rates and higher dispersal distances than passerine populations at the core of their range.

Key Words: Yellow-breasted Chat, Icteria virens auricollis, northern periphery of range, return rates, site fidelity, natal philopatry, apparent local survival, British Columbia.

A population of the western subspecies of the Yellowbreasted Chat (Icteria virens auricollis) designated as endangered by the Committee on the Status of Endangered Wildlife in Canada (COSEWIC 2011*) occurs within a very restricted area in British Columbia at the northern tip of its range (Eckerle and Thompson 2001). Sites at the periphery of a species' range have occasionally been shown to be very important for conserving endangered species and biodiversity (Channel and Lomolino 2000).

The breeding range of the Yellow-breasted Chat (Icteria virens) extends from Mexico to southern Canada (Eckerle and Thompson 2001). In Canada, the western subspecies breeds in southeastern Alberta, southern Saskatchewan, south-central British Columbia, and the extreme southwestern portion of British Columbia (Eckerle and Thompson 2001). The eastern subspecies (I. virens virens) breeds in Canada in southern Ontario (Eckerle and Thompson 2001).

In British Columbia, the Yellow-breasted Chat breeds only within $100 \mathrm{~km}$ of the U.S. border, in the Similkameen, Okanagan, and Kootenay river valleys (Eckerle and Thompson 2001; Dulisse et al. 2005). In the southern Okanagan River valley in British Columbia, Yellowbreasted Chats nest exclusively in riparian thickets. At least $87 \%$ of this habitat has been converted to urban and agricultural development (Lea 2008). The population size of the Yellow-breasted Chat in British Columbia was estimated to be less than 152 breeding pairs
(COSEWIC 2011*), but the fecundity of this population is similar to southern populations of Yellow-breasted Chats (Morgan et al. 2007).

To ensure effective management, conservation, and recovery of an endangered species and its habitat, it is essential to have a basic understanding of dispersal dynamics (Saunders et al. 1991; Fahrig and Merriam 1994). Data on demographic variables such as survival, dispersal, and site fidelity are essential for conservation, restoration, and management of species (Woolfenden et al. 2001; Sillett and Holmes 2002; Sedgwick 2004). If site fidelity is low and birds disperse regularly, management strategies for restoring and creating habitat may not be effective because the populations will not necessarily be concentrated in high-quality habitat (Schlossberg 2009). However, if site fidelity is high, management will be more straightforward because the population will be more closed (Robinson and Morse 2000).

There has been very little study of the demography of $I$. virens, and most research has been done on the eastern subspecies (e.g., Thompson and Nolan 1973; Burhans and Thompson 1999; Ricketts and Ritchison 2000; Lehnen and Rodewald 2009). The objective of this study was to fill data gaps on demography of this endangered population to better understand the potential for the population to persist in this fragmented landscape. 


\section{Study Area}

The study area (Figure 1) is within the riparian zone of the Okanagan River in the southern Okanagan valley in British Columbia, between Penticton $\left(49^{\circ} 27^{\prime} \mathrm{N}\right.$, $\left.119^{\circ} 36^{\prime} \mathrm{W}\right)$ and Osoyoos $\left(49^{\circ} 1^{\prime} \mathrm{N}, 119^{\circ} 26^{\prime} \mathrm{W}\right)$ on the U.S. border, a distance of $66 \mathrm{~km}$. Elevation of study sites ranged from $297 \mathrm{~m}$ to $344 \mathrm{~m}$ above sea level. Owing to sensitivity among landowners regarding the occurrence of species at risk on their lands, the nine study sites are not identified on the map of the study area (Figure 1).

The riparian habitat within the Okanagan valley south of Penticton is highly fragmented by urban and agricultural development, and it consists of nine discontinuous patches that, prior to 1938 (Lea 2008), were connected within tributaries and drainage lines of the Okanagan River. A study site was defined as a patch of contiguous riparian habitat containing no shrub-steppe habitat or urban or agricultural development. Each study site consisted of a strip of riparian habitat between 0.05 and $1 \mathrm{~km}$ in width and between 0.25 and $4.5 \mathrm{~km}$ in length. Study sites contained between 2 and 38 territories.

The tree layer consisted mainly of Black Cottonwood (Populus trichocarpa), Water Birch (Betula occidentalis), willows (Salix spp.), and Mountain Alder (Alnus incana subsp. tenuifolia), and the shrub layer was dominated by wild roses (Rosa acicularis, $R$. nutkana, $R$. woodsii, and $R$. gymnocarpa) with Common Snowberry (Symphoricarpos albus), Saskatoon (Amelanchier alnifolia), and Red-osier Dogwood (Cornus stolonifera). The herbaceous layer included a variety of grass and wildflower species (Morgan et al. 2006). Wild roses are the main shrub species used by Western Yellowbreasted Chats for breeding (McKibbin and Bishop 2010), and suitable breeding habitat was defined as containing wild rose and other riparian species noted above.

The sizes of study sites and dispersal distances were measured with ArcGIS 9.0 (ESRI 1999*). The combined area of the nine study sites was 189.4 ha. Individually, study sites ranged in size from 1.4 to 89.2 ha (mean of 21.04 ha, SD 28.67). Study sites one to seven were in the south of the study area between 3 and $18 \mathrm{~km}$ apart. Study site nine was $28 \mathrm{~km}$ north of the nearest site to the south. Study site eight was between the northern and southern study sites.

Three banding stations in the Monitoring of Avian Productivity and Survivorship Program (MAPS) (DeSante et al. 2001) were within our study area. All Western Yellow-breasted Chats $(n=8)$ colour-banded at those stations were included in the study. Western Yellow-breasted Chats banded outside the nine study sites $(n=5)$ were from "other" sites without suitable breeding habitat. Those Western Yellow-breasted Chats, which were banded at the beginning of the breeding season, were not observed again. They were likely moving through and did not breed.
During the study years, $>90 \%$ of suitable habitat in the southern Okanagan valley (Lea 2008) was surveyed for Western Yellow-breasted Chats, and it was therefore unlikely that Western Yellow-breasted Chats breeding in the study area were not detected. The nine study sites represented the areas where there was a concentration of Western Yellow-breasted Chats.

\section{Methods}

\section{Field surveys}

Each study site was visited approximately every three to four days between mid-May and late July in 2001 to 2007 to determine whether singing males were present. The observer sat quietly for 10 minutes; if no Western Yellow-breasted Chats were detected, the recorded tape of a singing male Yellow-breasted Chat was played for 30 seconds, followed by a 2 -minute silence, during which the observer listened and watched for a reaction. If no Western Yellow-breasted Chats were seen or heard, the tape was replayed once before the observer moved $50 \mathrm{~m}$ to the next suitable area. A minimum of 20 to 30 minutes was spent in each potential breeding habitat.

If a Western Yellow-breasted Chat was observed or was heard singing, the potential territory was revisited within four days; if the male was still present, territory occupancy was confirmed. A confirmed territory was monitored every three to four days to determine whether a female was present and whether the adults were banded, to locate nests, and to confirm breeding. If adults were banded, we attempted to read the colour bands with binoculars and/or spotting scopes. Band combinations of an individual were accepted as accurate after two consistent observations, preferably by two different observers, on separate visits to the territory. Nests were located by following Western Yellowbreasted Chats that were carrying nesting material or food and by listening for audible clues made by the female when on or near a nest, and then systematically searching through the wild rose patch. Territories and nests were monitored throughout the breeding season following Morgan et al. (2006).

Methodology for mist-netting and colour-banding of adults are described in McKibbin and Bishop (2008). Nestlings were banded at age six days.

\section{Demographic variables}

Methodology for mapping of breeding territories is described in McKibbin and Bishop (2010). Mean territory size was 0.37 ha (SD 0.27, $n=66$ ) (McKibbin and Bishop 2010). A territory was considered the same as in previous years if the male sang or defended an area within the boundaries of the territory from other years of the study.

We estimated apparent survival, not actual survival (Baker et al. 1995), because our estimates do not distinguish between mortality and permanent dispersal (Lebreton et al. 1992). Return rate was defined as the 


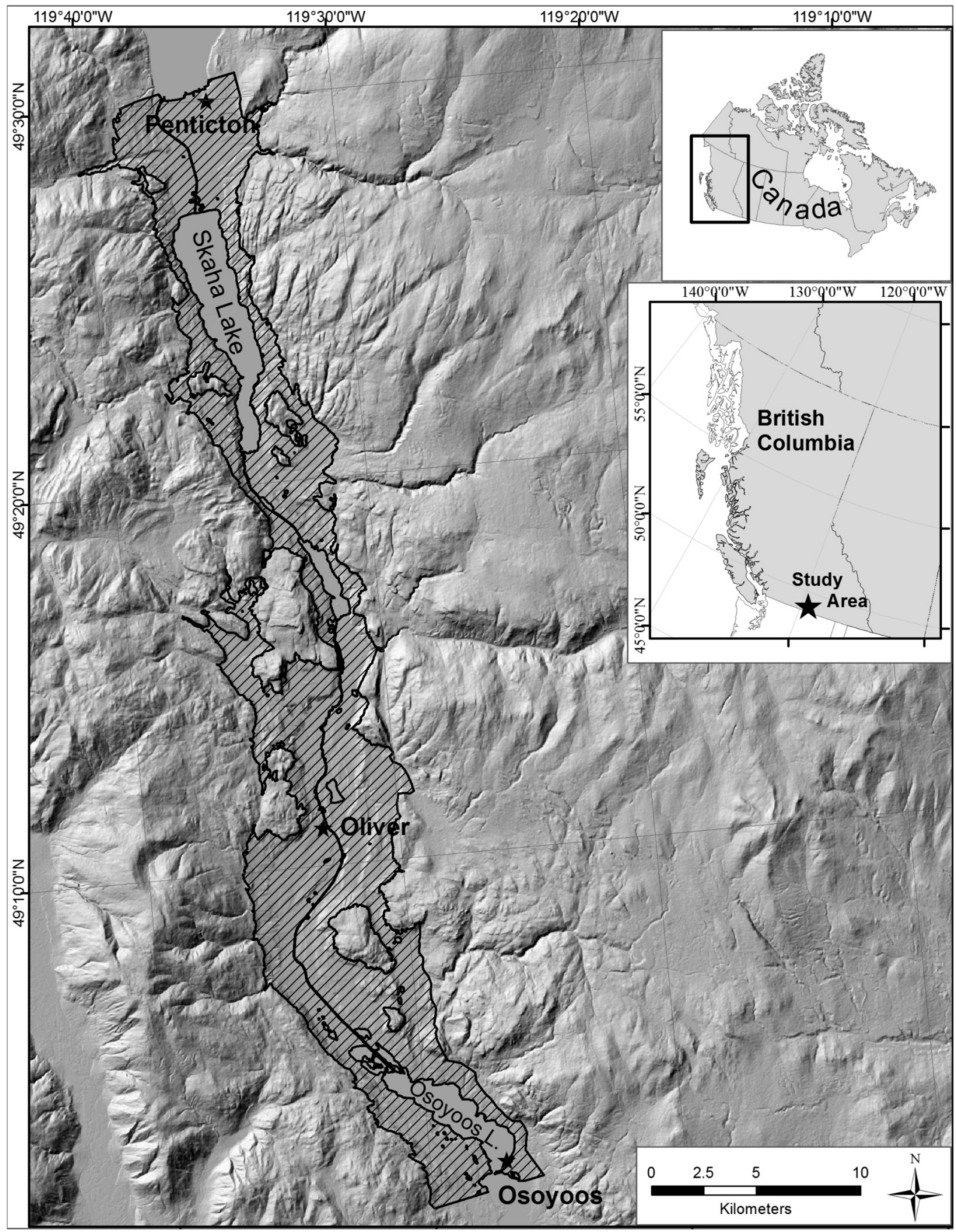

FIGURE. 1. Western Yellow-breasted Chat (Icteria virens auricollis) study area in the southern Okanagan valley, British Columbia.

percentage of colour-banded Western Yellow-breasted Chats recaptured or re-sighted in the southern Okanagan valley the following year or during the study period
(Sandercock 2006). Site fidelity was defined as the percentage of colour-banded Western Yellow-breasted Chats originally banded as adults on a particular study 
site that returned to the same study site the following year. Dispersal was defined as the distance $(\mathrm{km})$ from the centre of the territory (determined by ArcGIS 9.0) in which the bird was banded to the centre of a new territory in a different study site occupied in later years. A bird was considered to have dispersed if it moved from one of the nine study sites to another, not if it moved to a different territory within the same study site. Natal dispersal was defined as the distance $(\mathrm{km})$ from the centre of the territory where the Western Yellow-breasted Chat was born to the centre of the territory that it occupied the following year (year 1). Territory fidelity was defined as the percentage of adults that used the same breeding territory in consecutive years.

\section{Statistical analysis}

Apparent survival of male Western Yellow-breasted Chats banded as adults $(n=45)$ based on banding and re-sighting data was estimated using Program MARK and compared by sequential models to test for effect of year on survival estimates and recapture rates (White and Burnham 1999). For this study, only two parameters, namely, apparent survival $(\phi)$ and recapture probability $(p)$, were used, and therefore four different Akaike information criterion (AIC) models (Burnham and Anderson 1998) were fitted to the data, namely $\phi(\mathrm{t}) p(\mathrm{t})$ (survival and probability of recapture is time dependent), $\phi() p.($.$) (survival and probability of recap-$ ture is constant), $\phi(\mathrm{t}) p($.$) (survival is time-dependent$ and probability of recapture is constant), and $\phi() p.(\mathrm{t})$ (survival is constant and probability of recapture is time-dependent) ( $\phi=$ apparent survival, $p=$ recapture probability, $\mathrm{t}=$ time (year), $()=$. constant).

We tested the model $\phi(\mathrm{t}) p(\mathrm{t})$ using bootstrapped goodness of fit over 1000 simulations in Program MARK (2010). The same analysis was performed combining the data of the 45 males banded as adults that returned in subsequent years and the 26 males banded as nestlings that returned in subsequent years but excluding their first interval. There were not enough resightings of females banded as adults and nestlings to support mark-recapture analysis. Return rates for nestlings were therefore estimated as a percentage of Western Yellow-breasted Chats banded as nestlings and resighted or recaptured the following year or during the study period, and return rates for females banded as adults were therefore estimated as a percentage of colour-banded females re-sighted or recaptured the following year or during the study period (Sandercock 2006).

Dispersal distances of males banded as nestlings were compared with those of females banded as nestlings, and dispersal distances of males banded as nestlings were compared with those of males banded as adults. Because of small sample size, non-parametric statistics were used. A Wilcoxon rank sum test was done to determine significant differences between dispersal distances. Statistical analysis was performed using the software JMP IN version 4 (SAS Institute Inc.).
TABLE 1. Number of WesternYellow-breasted Chats (Icteria virens auricollis) colour-banded in the southern Okanagan valley, British Columbia, during the period 2001-2006.

\begin{tabular}{ccccc}
\hline \hline & \multicolumn{3}{c}{ Banded as adults } & \\
\cline { 2 - 4 } Year & Males & Females & Total & Banded as nestlings \\
\hline 2001 & $6^{*}$ & 1 & 7 & 15 \\
2002 & 8 & $4^{* *}$ & 12 & 46 \\
2003 & 6 & 7 & 13 & 54 \\
2004 & 5 & $5 * *$ & 10 & 47 \\
2005 & 10 & $5 * *$ & 15 & 91 \\
2006 & 10 & 8 & 18 & 132 \\
Total & 45 & 30 & 75 & 385 \\
\hline \hline
\end{tabular}

* Includes 2 banded outside the nine study sites

** Includes 1 banded outside the nine study sites

\section{Results}

Apparent survival estimate and return rates

In 2001 through 2006, we colour-banded 75 adults and 385 nestlings (Table 1). A goodness of fit test on the data for males banded as adults $(n=45)$ determined that the global model $\phi(\mathrm{t}) p(\mathrm{t})$ (survival and probability of recapture is time-dependent) fit the data (bootstrapped goodness of fit $P=0.17$ ). The model that fit our data the best (the model with the lowest $\mathrm{AIC}_{c}$ for males banded as adults) indicated that survival $(\phi)$ and probability of recapture $(p)$ were constant (Table 2 ). Apparent survival estimate for males for the best model was 0.65 (SE 0.07, 95\% CI 0.5-0.77).

When the data of the 45 males banded as adults that returned in subsequent years and the 26 males banded as nestlings that returned in subsequent years (excluding their first interval) were combined, a goodness of fit test indicated that the data fit the global model (bootstrapped goodness of fit $P=0.12$ ). The best model indicated that survival $(\phi)$ and probability of recapture $(p)$ were constant (Table 3). Apparent survival estimate for the best model was 0.66 (SE 0.06, 95\% CI 0.53-0.77).

To compare (1) adults that may have arrived in the southern Okanagan valley from somewhere else and then remained with (2) fledged birds that survived into adulthood and stayed, we analyzed males banded as adults and the combined group of males banded as adults and nestlings.

Of the 45 males that were banded as adults, $20(44 \%)$ were re-sighted in subsequent years (2002-2007): 15 of the 20 males were first re-sighted the next year after being banded, 4 were first re-sighted two years after being banded, and 1 was first re-sighted three years after being banded. Four (13\%) of the 30 females that were banded as adults were re-sighted in the southern Okanagan valley during the period 2002-2007. Three females were re-sighted the year after being banded and 1 female was re-sighted two years after being banded.

\section{Adult site fidelity and dispersal}

Fourteen males (31\%) of 45 returned to the same study site the year after being banded [(an additional three males also returned to the same study site between 
two and three years after being banded, for a total of 17). (Of the 17 males, 12 males also showed territory fidelity by breeding between two and at least five years in the same territory.)] Of the 17 males, 2 bred at the same study site for at least five years, 5 bred at the same study site for at least three years, and 8 bred at the same study site for at least two years. Finally, 2 of the 17 males dispersed the year after they were banded but then bred for at least two years at the same study.

The males $(n=5)$ that did not show between-year site fidelity were observed between 6.4 and $42.9 \mathrm{~km}$ from the sites where they had been banded, and they maintained territories in the years that they were banded. The median dispersal distance was $8.14 \mathrm{~km}$ (mean $14.98 \mathrm{~km}, \mathrm{SD} 15.7)$. These observations were made between one and three years after the males were banded.

The three (10\%) of the 30 females that were colourbanded as adults and re-sighted the year after being banded all bred for at least two years in the same study site.

No mate fidelity was observed during the study years 2002 to 2007.

It was uncommon for Western Yellow-breasted Chats to relocate their territories during the breeding season. There was only one known occasion when a male relocated to a different study site during the breeding season. This male was detected $12.3 \mathrm{~km}$ from his original territory about 10 days after his first nest failed and the female disappeared. The male stayed and defended his second territory for the remainder of the breeding season. A female was detected in the second territory, but we were unable to locate a nest.

\section{Natal philopatry and dispersal}

None of the colour-banded nestlings returned to breed in their natal territory. Thirty-nine $(10 \%)$ of the 385 chats banded as nestlings returned to the southern Okanagan valley during the period 2002-2007; 26 were males and 13 were females. Sixteen $(62 \%)$ of the 26 males and $7(54 \%)$ of the 13 females that were resighted in the southern Okanagan valley returned to their natal sites.

Of the 10 males that were banded as nestlings and returned to breed in a study site other than their natal site, 7 were observed in year 1 . These 7 males dispersed between 2.5 and $15.6 \mathrm{~km}$. The median dispersal distance was $10.3 \mathrm{~km}$ (mean $10.2 \mathrm{~km}$, SD 4.5). Of the 6 females that were banded as nestlings and were resighted, 2 were observed in year 1 . The dispersal distances were 2.3 and $2.6 \mathrm{~km}$. The median and mean dispersal distances for these females were both $4.2 \mathrm{~km}$ (SD 0.2). There was no significant difference between dispersal distances for males $(n=7)$ and females $(n=2)$ banded as nestlings and observed in year 1 (Wilcoxon rank sum test, $\chi^{2}=3.09, \mathrm{df}=1, P=0.079$ ). There was no significant difference in dispersal distance of males banded as adults $(n=5)$ and males banded as nestlings $(n=7)$ (Wilcoxon rank sum test, $\chi^{2}=0.24, \mathrm{df}=1$, $P=0.63)$.
TABLE 2. Models for estimating local survival of Western Yellow-breasted Chat (Icteria virens auricollis) males banded as adults $(n=45)$ in the southern Okanagan valley, British Columbia, during the period 2001-2007. $\phi=$ apparent survival, $p=$ recapture probability, $\mathrm{t}=$ time (year), $()=$. constant.

\begin{tabular}{lcrcc}
\hline \hline Model & $\mathrm{AIC}_{c}$ & $\Delta \mathrm{AIC}_{c}$ & $\mathrm{AIC}_{c}$ weight & Deviance \\
\hline$\phi() p.()$. & 133.57 & 0.00 & 0.87 & 47.42 \\
$\phi() p.(\mathrm{t})$ & 137.74 & 4.18 & 0.11 & 39.89 \\
$(\mathrm{t}) p()$. & 141.02 & 7.45 & 0.02 & 43.16 \\
$\phi(\mathrm{t}) p(\mathrm{t})$ & 144.82 & 11.26 & 0.00 & 36.06 \\
\hline \hline
\end{tabular}

TABLE 3. Models for estimating local survival of Western Yellow-breasted Chat (Icteria virens auricollis) males banded as adults and males banded as nestlings that returned in subsequent years, excluding the first interval $(n=71)$ in the southern Okanagan valley, British Columbia, during the period 2001-2007. $\phi=$ apparent survival, $p=$ recapture probability, $\mathrm{t}=$ time $($ year $),()=$. constant.

\begin{tabular}{lcrcc}
\hline \hline Model & $\mathrm{AIC}_{c}$ & \multicolumn{1}{c}{$\Delta \mathrm{AIC}_{c}$} & $\mathrm{AIC}_{c}$ weight & Deviance \\
\hline$\phi(.) \mathrm{p}()$. & 196.9197 & 0.0000 & 0.95508 & 61.4770 \\
$\phi(.) \mathrm{p}(\mathrm{t})$ & 203.5567 & 6.6370 & 0.03458 & 57.0203 \\
$\phi(\mathrm{t}) \mathrm{p}()$. & 206.0828 & 9.1631 & 0.00978 & 59.5464 \\
$\phi(\mathrm{t}) \mathrm{p}(\mathrm{t})$ & 211.8140 & 14.8943 & 0.00056 & 55.4950 \\
\hline \hline
\end{tabular}

\section{Discussion}

Our estimates of return rates, especially for females, are probably an underestimate. Yellow-breasted Chats are elusive and occur in dense bush habitat (Eckerle and Thompson 2001). They have a skulking and secretive nature and, unless they are detected while singing, are often overlooked (Thompson and Nolan 1973; Eckerle and Thompson 2001). Females are more secretive than males, and in our experience an entire breeding season can pass without a sighting of a "nesting" female. Even males often sing from high perches or dense thickets, and this makes reading of colour bands difficult. For example, in this study, up to six hours were spent in a territory throughout the breeding season without any success reading colour bands of some males.

Even though our return rates are an underestimate, our rates of $44 \%$ for males banded as adults and $13 \%$ for females banded as adults during the six-year period are higher than the return rates for the Eastern Yellowbreasted Chat in the core of its range in southern Indiana, where only $11 \%$ of breeding males returned and none of the females were re-sighted during a five-year study period (Thompson and Nolan 1973). Our return rates are combined for all study sites in an area of 189.4 ha, whereas the study in southern Indiana was conducted at one intensively studied site (three fields, a total of $18 \mathrm{ha}$ ). This may account for the higher return rates in the southern Okanagan valley. However, during the three years of the Indiana study, observations were 
made as well as mist-netting, and Yellow-breasted Chat tape-recordings were used to detect banded Yellowbreasted Chats on 49 ha of additional nearby fields. Return rates of resident males for the study area (18 ha) and the additional fields (49 ha) were still only $13 \%$, much lower than in the southern Okanagan valley. In southeastern Ohio, the return rate for Yellow-breasted Chats (males and females combined) during a five-year study (2002-2006) in regenerating shrubland patches 4 to 18 ha in size within a 1000 ha state forest was 19.8\% (Lehnen and Rodewald 2009).

Our detected return rates might also be higher because there is little riparian habitat left in the southern Okanagan valley and our population is relatively concentrated. These likely increases the chance of detection compared to the other studies, where there might be larger areas of suitable habitat to search. However, the lack of habitat suggests that birds in British Columbia would not be able to find suitable breeding sites and would be less inclined to return, or they might return and be unsuccessful and leave and/or not return again.

The return rate of $44 \%$ for males is within the range of 7\%-66\% reported for other long-term studies of migratory passerines in North America (e.g., Best and Rodenhouse 1984; Lanyon and Thompson 1986; DiQuinzio et al. 2001; Beheler et al. 2003; Howlett and Stutchbury 2003; Sedgwick 2004; Schlossberg 2009 ), and our site fidelity of $31 \%$ is lower than the $50 \%-76 \%$ reported in the same studies. However, comparisons are sometimes difficult to make because some studies do not clearly define the methodology used to determine return rates and site fidelity and because differences in habitat and behaviour could also account for differences in return rates and site fidelity.

While there are no comparable data on apparent survival in Yellow-breasted Chats elsewhere, the apparent survival rate of $65 \%$ (66\% combined) for male Western Yellow-breasted Chats in the southern Okanagan valley was at the high end of the range of $43 \%-70 \%$ for survival rates for long-term studies of migratory songbirds (e.g., Budnik et al. 2000; Bayne and Hobson 2002; Jones et al. 2004; Ward 2005; Fletcher et al. 2006; Schlossberg 2009; Cox and Jones 2010). Return rate in the Okanagan for adult male chats was $44 \%$ and apparent survival was $65 \%$, which is still a minimum survival estimate because it does not account for males that could have survived but dispersed outside of the study area. This also implies that estimated return rates for females (13\%) and nestlings (10\%) were probably an underestimate of survival. Once again, apparent survival does not account for dispersal outside of the study area or, especially for females, incomplete detection. Other studies (e.g., Cilimburg et al. 2002) also reported return rates to be an underestimate of survival.

The maximum natal dispersal distance of $15.6 \mathrm{~km}$ for male Western Yellow-breasted Chats $(n=7)$ was greater than the maximum natal dispersal distance of $2.6 \mathrm{~km}$ for females $(n=2)$. It is possible that more females dispersed beyond the study area or were not re-sighted. This contrasts with Eastern Phoebes (Sayornis phoebe), where the average dispersal distance for females (3115 m, SD 958) was slightly greater than for males (1486 m, SD 340) (Beheler et al. 2003). In southeastern Ohio, the dispersal distances for nine shrubland species (males and females combined) tended to be larger in natal dispersers (second-year birds returning) than breeding dispersers (after-second-year birds returning) (Lehnen and Rodewald 2009). This contrasts with our study, where, on average, breeding males moved farther than natal males and females that dispersed, but our sample size for females is small.

Our natal philopatry in the south Okanagan of $10.1 \%$ falls at the high end of the range of typical rates $(0 \%-$ $16 \%$ ) for long-term studies of North American migratory species (e.g., DiQuinzio et al. 2001; Sedgwick 2004; Schlossberg 2009; Ward 2005). None of the Eastern Yellow-breasted Chat nestlings banded in Indiana returned to their natal site in subsequent years (Thompson and Nolan 1973). In southeastern Ohio, $0.8 \%$ of banded Eastern Yellow-breasted Chat juveniles returned in subsequent years (Lehnen and Rodewald 2009).

Population densities are not always equal throughout the geographic range of a species, and there is often a higher density in the core area than in peripheral areas (Whittaker 1967; Westman 1980; Maurer and Brown 1989). Populations occurring at the periphery of a species' range may experience more unpredictable environmental conditions (Maurer and Brown 1989) or suboptimal conditions (Sanz 1997); productivity can be more variable (Mahony et al. 2006); populations may experience stronger selection, immigration, and dispersal (Holt and Gomulkiewicz 1997; Kirkpatrick and Barton 1997); and between-year return rates can be lower (Sanz 2001). However, our data indicate that the southern Okanagan valley Western Yellow-breasted Chat population at the northern periphery of this species' range has higher survival, site fidelity, and return rates than other Yellow-breasted Chat populations and rates are comparable to those of migratory passerines in long-term studies throughout North America. These findings suggest that, despite fragmentation and an $87 \%$ reduction in riparian habitat (Lea 2008), the quality of the remaining riparian thickets is adequate to support a small population with relatively high rates of return for juvenile and adult Western Yellow-breasted Chats and reasonable rates of productivity (Morgan et al. 2007).

In this narrow agricultural valley, the southern Okanagan Western Yellow-breasted Chat population is small but thriving and may be limited only by availability of suitable habitat. Some evidence of this is the recent expansion in the number of Western Yellowbreasted Chat territories in locations where cattle grazing has been more restricted than in past years. About half of our study area is grazed by cattle in the winter and into the spring before 1 May each year. The live- 
stock grazing and movement through the riparian areas cause fragmentation of the understory and damage to the shrub thickets used by Western Yellow-breasted Chats. As a result of the enforcement of the seasonal restrictions on livestock grazing by the British Columbia Ministry of Environment after 2002, wild roses and mixed shrub thickets appear to be recovering, and there was a $42 \%$ increase in the number of Western Yellowbreasted Chat territories in study site two between 2002 and 2007. We predict that if additional habitat restoration efforts are initiated, the response will be an expansion in the distribution and population size of the Western Yellow-breasted Chat population in the southern Okanagan valley in future decades.

\section{Acknowledgements}

We thank the Osoyoos Indian band, the En'owkin Centre, Audra Moir, Marta Sutherland, and Jim Heel for access to their land. We also thank Alicia Newbury, Barry Lancaster, Clarence Louie, Dave Nield, Ingrid Pollet, Jason Emery, Jeanette Armstrong, Jukka Jantunen, Lukus Bent, Mario Hall, Michael Bezener, Nancy Mahony, Owain McKibbin, Richard Armstrong, Richard Cannings, Ron Hall, Rosemary Bryan, Steve Bryson and Tawna Morgan for their assistance during data collection and Dan Shervill for GIS analysis. We thank reviewers for valuable suggestions. Scientific permit to capture and band migratory birds 10365 CY and Species at Risk Act permits 59-05-0378, 5906-0304, and 59-07-0279 were granted to René McKibbin. The project was reviewed by Animal Care Committees at Simon Fraser University and the British Columbia Ministry of the Environment. The study was funded by Environment Canada, the En'owkin Centre, and the Osoyoos Indian Band.

\section{Documents Cited (marked * in text)}

COSEWIC. 2011. COSEWIC assessment and status report on the Yellow-breasted Chat auricollis subspecies Icteria virens auricollis and the Yellow-breasted Chat virens subspecies Icteria virens virens in Canada. Committee on the Status of Endangered Wildlife in Canada. Ottawa. xvi +51 pages. (www.registrelep-sararegistry.gc.ca/default _e.cfm). Program Mark. 2010. A Gentle introduction. http: //www.phidot.org/software/mark/index.html (Accessed 6 August 2010).

ESRI. 1999. ArcGIS, version 9.0. Environmental Systems Research Institute, Redlands, California.

\section{Literature Cited}

Baker, M., N. Nur, and G. R. Geupel. 1995. Correcting biased estimates of dispersal and survival due to limited study area: theory and application using Wrentits. Condor 97: 663-674.

Bayne, E. M., and K. A. Hobson. 2002. Annual survival of adult American Redstarts and Ovenbirds in the southern boreal forest. Wilson Bulletin 114: 358-367.

Beheler, A. S., O. E. Rhodes, Jr., and H. P. Weeks, Jr. 2003. Breeding site and mate fidelity in Eastern Phoebes (Sayornis phoebe) in Indiana. Auk 120: 990-999.
Best, L. B., and N. L. Rodenhouse. 1984. Territory preference of Vesper Sparrows in cropland. Wilson Bulletin 96: 72-82.

Budnik, J. M., M. R. Ryan, and F. R. Thompson, III. 2000. Demography of Bell's Vireos in Missouri grassland-shrub habitats. Auk 117: 925-935.

Burhans, D. E., and F. R. Thompson, III. 1999. Habitat patch size and nesting success of Yellow-breasted Chats. Wilson Bulletin 111: 210-215.

Burnham, K. P., and Anderson, D. R. 1998. Model Selection and Inference: a Practical Information-Theoretic Approach. (Springer-Verlag: New York.)

Channell, R., and M. V. Lomolino. 2000. Dynamic biogeography and conservation of endangered species. Nature 403: 84-86.

Cilimburg, A. B., M. S. Lindberg, J. J. Tewksbury, and S. J. Hejl. 2002. Effects of dispersal on survival probability of adult Yellow Warblers (Dendroica petechia). Auk 119: 778-789.

Cox, J. A., and C. D. Jones. 2010. Estimating probabilities of survival of male Bachman's Sparrows from plot-based, mark-resighting, off-plot surveys and multi-strata models. Condor 112: 663-669.

DeSante, D. F., K. M. Burton, P. Velez, and D. Froehlich. 2001. MAPS Manual: 2001 Protocol. Institute for Bird Populations, Point Reyes Station, California. 67 pages.

DiQuinzio, D. A., P. W. C. Paton, and W. R. Eddleman. 2001. Site fidelity, philopatry, and survival of promiscuous Saltmarsh Sharp-tailed Sparrows in Rhode Island. Auk 118: 888-899.

Dulisse, J. A., S. K. Ogle, and M. M. Machmer. 2005. First nest record for Yellow-breasted Chat (Icteria virens auricollis) in southeastern British Columbia. Northwest Naturalist 86: 160-162.

Eckerle, K. P., and C. F. Thompson. 2001. Yellow-breasted Chat (Icteria virens). No. 575 in The Birds of North America. Edited by A. Poole and F. Gill. Academy of Natural Sciences, Philadelphia, and American Ornithologists' Union, Washington.

Fahrig, L., and G. Merriam. 1994. Conservation of fragmented populations. Conservation Biology 8: 50-59.

Fletcher Jr., R. J., R. R. Koford, and D. A. Seaman. 2006. Critical demographic parameters for declining songbirds breeding in restored grasslands. Journal of Wildlife Management 70: 145-157.

Holt, R. D., and R. Gomulkiewicz. 1997. How does immigration influence local adaptation? A reexamination of a familiar paradigm. American Naturalist 149: 563-572.

Howlett, J. S., and B. J. M. Stutchbury. 2003. Determinants of between-season site, territory, and mate fidelity in Hooded Warblers (Wilsonia citrina). Auk 120: 457-465.

Jones, J., J. J. Barg, T. S. Sillett, M. L. Veit, and R. J. Robertson. 2004. Minimum estimates of survival and population growth for Cerulean Warblers (Dendroica cerulea) breeding in Ontario, Canada. Auk 121: 15-22.

Kirkpatrick, M., and N. H. Barton. 1997. Evolution of a species' range. American Naturalist 150: 1-23.

Lanyon, S. M., and C. F. Thompson. 1986. Site fidelity and habitat quality as determinants of settlement pattern in male Painted Buntings. Condor 88: 206-210.

Lea, T. 2008. Historical (pre-settlement) ecosystems of the Okanagan Valley and Lower Similkameen Valley of British Columbia - pre-European contact to the present. Davidsonia 19: 3-38. 
Lebreton, J. D., K. P. Burnham, J. Clobert, and D. R. Anderson. 1992. Modeling survival and testing biological hypotheses using marked animals: a unified approach with case studies. Ecological Monographs 62: 67-118.

Lehnen, S. E., and A. D. Rodewald. 2009. Dispersal, interpatch movements, and survival in a shrubland breeding bird community. Journal of Field Ornithology 80: 242-252.

Mahony, N. A., P. G. Krannitz, and K. Martin. 2006. Seasonal fecundity of Sagebrush Brewer's Sparrow (Spizella breweri breweri) at the northern edge of its breeding range. Auk 123: 512-523.

Maurer, B. A., and J. H. Brown. 1989. Distributional consequences of spatial variation in local demographic processes. Annales Zoologica Fennici 26: 121-131.

McKibbin, R., and C. A. Bishop. 2008. Capture success rates of the western Yellow-breasted Chat in the south Okanagan valley, British Columbia, Canada during 2005 to 2007. North American Bird Bander 33: 179-184.

McKibbin, R., and C. A. Bishop. 2010. Habitat characterization of breeding territories of the western Yellow-breasted Chat in the south Okanagan, British Columbia, Canada. Northwestern Naturalist 91: 145-156.

Morgan, T. C., C. A. Bishop, and A. M. Bezener. 2006. Temporal fluctuation in abundance of Brown-headed Cowbirds and their hosts in riparian habitat in the Okanagan valley, British Columbia, Canada. Journal of Field Ornithology 77: 444-451.

Morgan, T. C., C. A Bishop, and T. D. Williams. 2007. Yellow-breasted Chat and Gray Catbird productivity in a fragmented western riparian system. Wilson Journal of Ornithology 119: 494-498.

Ricketts, M. S., and G. Ritchison. 2000. Nesting success of Yellow-breasted Chats: effects of nest site and territory vegetation structure. Wilson Bulletin 112: 510-516.

Robinson, S. K., and S. F. Morse. 2000. Conservation insights from demographic studies of migratory songbirds in the American Midwest. Pages 225-232 in Strategies for Bird Conservation: the Partners in Flight Planning Process. Edited by R. Bonney, D. N. Pashley, R. J. Cooper, and L. Niles. U.S. Department of Agrictulture, Forest Service, Rocky Mountain Research Station, Ogden, Utah.
Sandercock, B. K. 2006. Estimation of demographic parameters from live-encounter data: a summary review. Journal of Wildlife Management 70: 1504-1520.

Sanz, J. J. 1997. Geographic variation in breeding parameters of the Pied Flycatcher Ficedula hypoleuca. Ibis 139: 107114.

Sanz, J. J. 2001. Latitudinal variation in female local return rate in the philopatric Pied Flycatcher (Ficedula hypoleuca). Auk 118: 539-543.

Saunders, D. A., R. J. Hobbs, and C. R. Margules. 1991. Biological consequences of ecosystem fragmentation: a review. Conservation Biology 5: 18-32.

Schlossberg, S. 2009. Site fidelity of shrubland and forest birds. Condor 111: 238-246.

Sedgwick, J. A. 2004. Site fidelity, territory fidelity, and natal philopatry in Willow Flycatchers (Empidonax traillii). Auk 121: 1103-1121.

Sillett, T. S., and R. T. Holmes. 2002. Variation in survivorship of a migratory songbird throughout its annual cycle. Journal of Animal Ecology 71: 296-308.

Thompson, C. F., and V. Nolan, Jr. 1973. Population biology of the Yellow-breasted Chat (Icteria virens L.) in southern Indiana. Ecological Monographs 43: 145-171.

Ward, M. P. 2005. The role of immigration in the decline of an isolated migratory bird population. Conservation Biology 19: $1528-1536$.

Westman, W. E. 1980. Gaussian analysis: identifying environmental factors influencing bell-shaped species distributions. Ecology 61: 733-739.

White, G. C., and K. P. Burnham. 1999. Program MARK: survival estimation from populations of marked animals. Bird Study 46 (Suppl.): 120-138.

Whittaker, R. H. 1967. Gradient analysis of vegetation. Biological Review 42: 207-264.

Woolfenden, B. E., H. L. Gibbs, and S. G. Sealy. 2001. Demography of Brown-headed Cowbirds at Delta marsh, Manitoba. Auk 118: 156-166.

Received 15 February 2012

Accepted 28 June 2012 